\title{
Wieder einmal „Röntgenmessschablone“ und wieder einmal abgegolten
}

\author{
Auch im Beanstandungsgeschehen ist wechselnde Mode angesagt, durchaus auch im Retro- \\ Style. Gerade schießt man sich wieder auf "Röntgenschablonen“ ein, insbesondere wenn sie zu \\ zweit auf zwei Röntgenvollaufnahmen sind. Dabei ist schon der Begriff falsch: Es handelt sich \\ um Röntgenmessschablonen. Diese sind wieder die Zielscheibe, um damit die gesamte Leis- \\ tungsumgebung anzugreifen.
}

Die Röntgenmessschablone wird in der Berechnungsbestimmung zur Nr. 9000 „implantatbezogene Analyse“ erwähnt. Dort heißt es: „Bei Verwendung einer Röntgenmessschablone sind die Material- und Laborkosten gesondert berechnungsfähig.“ Dieser besondere Hinweis auf Material- und Laborkosten macht Sinn. Er soll darauf hinweisen, dass „Röntgenmessschablonen“ individuell angefertigt und berechnet werden. Für die Durchführung des eigentlichen Messvorgangs anhand eines Röntgenbildes beziehungsweise Ausmessen auf einem Röntgenbild werden in der Regel konfektionierte Maßteile in einen Träger (Schablone) eingebaut, zum Beispiel eine normierte Stahlkugel oder ein anderer, exakt dimensionstreuer Prüfkörper (zylindrische Röhre, Legostein etc.).

Die „Anwendung einer Röntgenmessschablone“ - in der GOZ unerwähnt - erfolgt perspektivisch „zur Festlegung der Implantatposition“, unmittelbar jedoch „zur metrischen Auswertung von radiologischen Befundunterlagen“, diese erwähnt unter der Nr. 9000 GOZ „implantatbezogene Analyse“.

Zur metrischen Auswertung muss logischerweise eine individuelle Röntgenmessschablone vor Anfertigung der betreffenden Röntgenbilder (Ä5002, Ä5004 oder Ä5095 ggf. zzgl. Ä5298 „digitales Röntgen“ oder auch Ä5370 „DVT“ zzgl. Ä5377 „3-DAuswertung“) bereits vorhanden und intraoral eingegliedert sein: Die Röntgenmessschablone wird „mitgeröntgt.“”

\section{Selbstständige, fakultativ erforderliche Leistung}

Um eine Röntgenmessschablone zahntechnisch herstellen $\mathrm{zu}$ können, sind eine vorausgehende Abformung und Planung notwendig. Um die Röntgenmessschablone beziehungsweise die da-

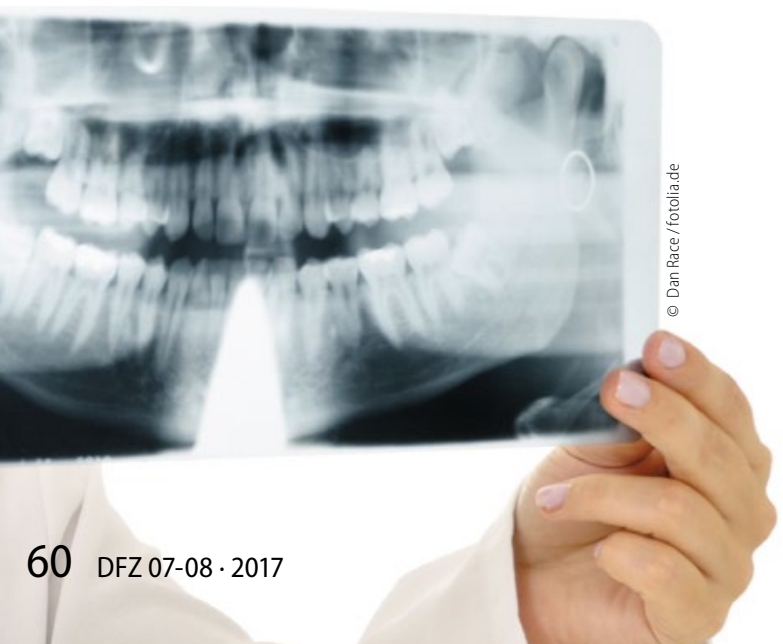

mit erzeugten Röntgenschatten aufs Bild bringen zu können, bedarf es der vorherigen intraoralen Einprobe und Eingliederung, was eine selbstständige, fakultative zahnärztliche Leistung im Vorfeld der Nr. 9000 ,implantatbezogene Analyse“ darstellt.

Diese zahnärztliche Leistung ist - so wie Röntgenaufnahmen in der Gebührenordnung für Ärzte (GOÄ) aufgeführt und wird entsprechend der Ziffer Ä2700 „Anlegen einer Hilfsvorrichtung" berechnet.

Diese zahnärztliche Leistung liegt den oben erwähnten, berechnungsfähigen Material- und Laborkosten zugrunde, wie jede Berechnung von Material- und Laborkosten dem Grunde nach auf einer erbrachten zahnärztliche Leistung beruht. Die zahnärztliche Leistung „Abformung, Planung und Eingliede-

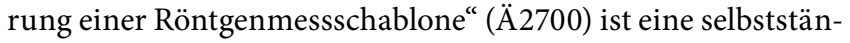
dige, fakultativ erforderliche und nur in Teilen delegierbare Leistung. Sie ist keineswegs mit den zahntechnischen Materialund Herstellungskosten und auch nicht mit der nachfolgenden Röntgenaufnahme abgegolten, schon gar nicht mit der wiederum nachfolgenden implantatbezogenen Analyse: Das Gegenteil zu behaupten, würde die Kausalitäten auf den Kopf stellen.

Es ist an dieser Stelle eine Grundsatzfestellung angebracht: Der Zahnarzt erhält für seine beruflichen Leistungen eine Vergütung in Form einer Gebühr.

Die Berechnung von Material- und Laborkosten für zahntechnische Leistungen erfolgt gemäß $\$ 9$ (1) GOZ neben der Berechnung von zugrunde liegenden Gebühren. Mit zahnärztlicher Gebührenberechnung können - sehr selten - bestimmte inkludierte Material- und Laborkosten abgegolten sein, mit der Berechnung von zahntechnischen Material- und Laborkosten aber niemals zahnärztliche Gebühren. Auch nicht die für die Benutzung zahntechnisch hergestellter Röntgenmessschablonen.

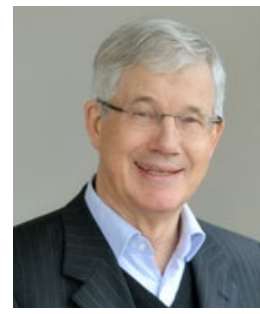

Dr. Peter H. G. Esser

GOZ-Experte und -Berater der ZA eG www.za-abrechnung.de 